\title{
Composição gravimétrica e peso específico dos resíduos sólidos urbanos em Jaú (SP)
}

\section{Gravimetric composition and specific weight of urban solid waste in Jaú (SP)}

\author{
Jozrael Henriques Rezende \\ Doutor em Ecologia e Recursos Naturais pela Universidade Federal de São Carlos (UFSCar) - São Carlos (SP), Brasil. Coordenador do Curso de Tecnologia \\ em Meio Ambiente e Recursos Hídricos da Faculdade de Tecnologia de Jahu (FATEC Jahu) - Jaú (SP), Brasil.
}

\section{Marina Carboni}

Doutora em Recursos Florestais pela Escola Superior de Agricultura "Luiz de Queiroz" (ESALQ/USP) - Piracicaba (SP), Brasil. Professora Assistente do Curso de Tecnologia em Meio Ambiente e Recursos Hídricos da FATEC Jahu - Jaú (SP), Brasil.

\section{Maurício Arruda de Toledo Murgel \\ Biólogo pela Universidade Sagrado Coração (USC) - Bauru (SP), Brasil. Secretário Municipal do Meio Ambiente de Jaú - Jaú (SP), Brasil.}

\section{Ana Luíza de Almeida Prado Capps}

Mestre em Desenvolvimento Regional e Meio Ambiente pelo Centro Universitário de Araraquara (UNIARA) - Araraquara (SP), Brasil. Diretora de Resíduos Urbanos da Secretaria Municipal do Meio Ambiente (SEMEIA) - Jaú (SP), Brasil.

\section{Heverton Leandro Teixeira \\ Especialista em Geoprocessamento Ambiental pela Universidade Federal de São Carlos (UFSCar) - São Carlos (SP), Brasil. Diretor de Áreas Verdes da SEMEIA - Jaú (SP), Brasil.}

\section{Gislaine Teresinha Capra Simões}

Especialista em Ecoturismo e Educação Ambiental pela Universidade Federal de Lavras (UFLA) - Jaú (SP), Brasil.

\section{Reinaldo Rogério Russi}

Discente do Curso de Meio Ambiente e Recursos Hídricos da FATEC JAHU. Estagiário da SEMEIA - Jaú (SP), Brasil.

\section{Bruna Letícia Romero Lourenço}

Discente do Curso de Meio Ambiente e Recursos Hídricos da FATEC JAHU. Estagiária da SEMEIA - Jaú (SP), Brasil.

\section{Cristina de Almeida Oliveira}

Discente do Curso de Meio Ambiente e Recursos Hídricos da FATEC JAHU. Estagiária da SEMEIA - Jaú (SP), Brasil.

\section{Resumo}

Este trabalho apresenta os resultados da avaliação dos resíduos sólidos domiciliares no município de Jaú (SP) por meio de amostragens realizadas em 2001 e 2010. Foram determinados a quantidade per capita, o peso específico e a composição gravimétrica dos resíduos sólidos urbanos gerados nos Jardins América e Ameriquinha em 2010, comparando os resultados obtidos aos da amostragem realizada em 2001 com a mesma metodologia. Constatou-se que a geração de resíduos aumentou 34,9\%, enquanto a população cresceu 29,6\% no período, levando a um incremento de 4,0\% na geração per capita de resíduos, que passou de $618 \mathrm{~g}$. hab-1. dia-1 para $643 \mathrm{~g}$. hab-1 dia $^{-1}$. Dos resíduos gerados no município, aproximadamente 50\% são de matéria orgânica, 25\% de rejeitos e $25 \%$ de materiais recicláveis, percentuais que pouco se alteraram nas duas amostragens. Entretanto, os resíduos do tipo "plástico mole", entre os recicláveis, foram aqueles cuja geração teve o maior aumento percentual (59\%) na avaliação.

Palavras-chave: composição gravimétrica; peso específico; resíduos sólidos urbanos. 


\section{Abstract}

This paper presents the results of the evaluation of urban solid waste in Jaú (SP) by means of samplings accomplished in 2001 and 2010 . There were determined the quantity per capita, the specific weight and the gravimetric composition of waste generated in the neighborhoods Jardim América and Ameriquinha in 2010 , comparing the results with a sample taken in 2001 with the same methodology. It was found that waste generation increased by $34.9 \%$ while the population grew $29.6 \%$, leading to an increase of $4.0 \%$ per capita in generation of waste, which increased from $618 \mathrm{~g}$. inhab-1. day ${ }^{-1}$ to $643 \mathrm{~g}^{\text {. inhab }}{ }^{-1}$. day ${ }^{-1}$. Waste generated in the county about is $50 \%$ organic matter, $25 \%$ wasting and $25 \%$ recyclable materials, percentages that have changed little in two samples. However, the soft plastic, among the recyclable material, was the one that had the largest increase (59\%) in the evaluation.

Keywords: gravimetric composition; specific weight; municipal solid waste.

\section{Introdução}

A crescente geração de resíduos devida ao aumento do consumo de toda a população está entre os maiores problemas ambientais da atualidade no País. Com a expansão e o adensamento das zonas urbanas, os problemas aumentam, visto que a infraestrutura sanitária da maioria das cidades brasileiras não acompanha o ritmo acelerado desse crescimento. Dados do Instituto Brasileiro de Geografia e Estatística (IBGE, 2002), oriundos da Pesquisa Nacional de Saneamento Básico, revelam que, no Brasil, os sistemas de limpeza urbana coletavam em torno de 150 mil toneladas de resíduos sólidos urbanos (RSU) por dia.

Do total de municípios na época da pesquisa, 63,6\% despejam seus resíduos em lixões, 18,4\% em aterros controlados e apenas $13,8 \%$ utilizam aterros sanitários. Atualmente mais de $80 \%$ da população brasileira vive na zona urbana, e a ABRELPE (2009) estima que a geração de resíduos sólidos urbanos no País foi de aproximadamente 57 milhões de toneladas no ano de 2009, sendo que cerca de 7 milhões de toneladas deixaram de ser coletadas e das 50 milhões coletadas 43\% tiveram destinação final inadequada.

A problemática da geração crescente de resíduos resultantes de sociedades caracterizadas pelo consumo predatório dos recursos naturais tem preocupado a maior parte dos países por conta dos impactos ambientais negativos gerados. Neste cenário, e considerando as premissas da sustentabilidade, um bom sistema municipal de resíduos sólidos urbanos deve medir, de alguma forma, a quantidade e a qualidade dos resíduos gerados pela sua população (POLAZ \& TEIXEIRA, 2009).

O planejamento deve começar, portanto, pela classificação e quantificação dos resíduos gerados, ou seja, é necessário inicialmente estimar a quantidade total e por habitante; realizar a análise da composição gravimétrica ou composição física (percentual de cada componente em relação ao peso total dos resíduos) e calcular o peso específico (peso dos resíduos em função do volume por eles ocupado, expresso em $\mathrm{kg} \cdot \mathrm{m}^{-3}$ ). Esta avaliação permite escolher a melhor destinação para cada tipo ou grupo de resíduos, possibilitando, desta forma, a segregação dos resíduos e rejeitos na fonte geradora.

Posteriormente deve ser definido o sistema de logística reversa com todos os seus componentes e, por fim, é implementado o programa de comunicação e educação ambiental visando garantir a eficácia da coleta seletiva, etapa fundamental no processo de gerenciamento integrado dos resíduos sólidos. A coleta seletiva tem por objetivo a separação ou pré-separação dos materiais que podem ser recuperados na própria fonte geradora, com acondicionamento diferenciado para cada material. Para este processo apresentar resultados satisfatórios, toda a comunidade deve estar inserida e participar do processo de separação dos resíduos sólidos recicláveis (FUZARO \& RIBEIRO, 2007).

O Gerenciamento Integrado de Resíduos Sólidos Urbanos (RSU) envolve diferentes órgãos da administração pública, do setor produtivo e da sociedade civil com o propósito de realizar a limpeza urbana, a coleta, o tratamento e a disposição final dos resíduos, com o objetivo de melhorar a qualidade de vida da população por meio do asseio da cidade. Para tanto é preciso considerar as características das fontes de produção, o volume e os tipos de resíduos gerados, as características sociais, culturais e econômicas dos cidadãos e as peculiaridades demográficas, climáticas e urbanísticas locais, para que se possa dar aos resíduos, tratamento diferenciado e disposição final técnica e ambientalmente corretas (MONTEIRO et al., 2001). Com o crescimento acelerado das cidades, o tipo de resíduos gerados mudou. A quantidade de embalagens nos resíduos urbanos, por exemplo, é cada vez maior. Por isso eles estão cada vez mais volumosos (SÃO PAULO, 2010).

Para o sucesso de qualquer programa de gerenciamento de resíduos é fundamental, portanto, conhecer detalhadamente o que se gera para planejar todo o sistema de gestão. Este planejamento deve considerar os conceitos indispensáveis de não geração e redução da geração de resíduos, e não somente a coleta, o transporte, a reciclagem e a destinação final. A implementação de um programa para o gerenciamento dos resíduos sólidos urbanos de um município representa um grande desafio, necessitando, para a sua efetivação, a participação e responsabilidade compartilhada entre o Poder Público, a população e o setor produtivo. A efetivação do planejamento será positiva se forem classificados e quantificados os resíduos sólidos gerados em uma cidade, já que esta é a etapa inicial do processo de gestão municipal dos resíduos urbanos, e determina as ações e modelos a serem adotados.

Os objetivos deste trabalho foram avaliar a geração de resíduos sólidos urbanos em 2010 no município de Jaú nos aspectos quantitativos 
(RSU gerados per capita e peso específico) e qualitativos (composição gravimétrica) e comparar os resultados obtidos com uma avaliação realizada em 2001, utilizando a mesma metodologia para a amostragem e determinação do peso específico e da composição gravimétrica.

\section{Materiais e métodos}

\section{Área de estudo}

O município de Jaú está localizado na região Centro-Oeste do estado de São Paulo, a aproximadamente $300 \mathrm{~km}$ da capital, e possui área total de $688,34 \mathrm{~km}^{2}$. Sua zona urbana tem aproximadamente $30 \mathrm{~km}^{2}$. Os municípios que se limitam territorialmente com a cidade são Mineiros do Tietê, Bocaina, Dois Córregos, Barra Bonita, Itapuí e Bariri. Segundo o IBGE (2010), lá vivem 131.050 habitantes, 97\% deles em zona urbana A amostragem para a classificação e quantificação dos resíduos gerados foi realizada nos bairros Jardim América e Ameriquinha, localizados na zona Nordeste de Jaú, conforme mostra a Figura 1

Em 2001, foi realizado estudo semelhante a este nos mesmos bairros, quando da efetivação do Programa "Jogue Limpo" (REZENDE, 2001), que tinha como objetivo principal implementar a coleta seletiva na cidade a partir de um projeto piloto que envolvia educação ambiental (palestras em escolas, visita às residências com distribuição de material educativo) e estratégias de marketing (carro de som, inserções em rádios e jornais, telemarketing) nos Jardins América e Ameriquinha.

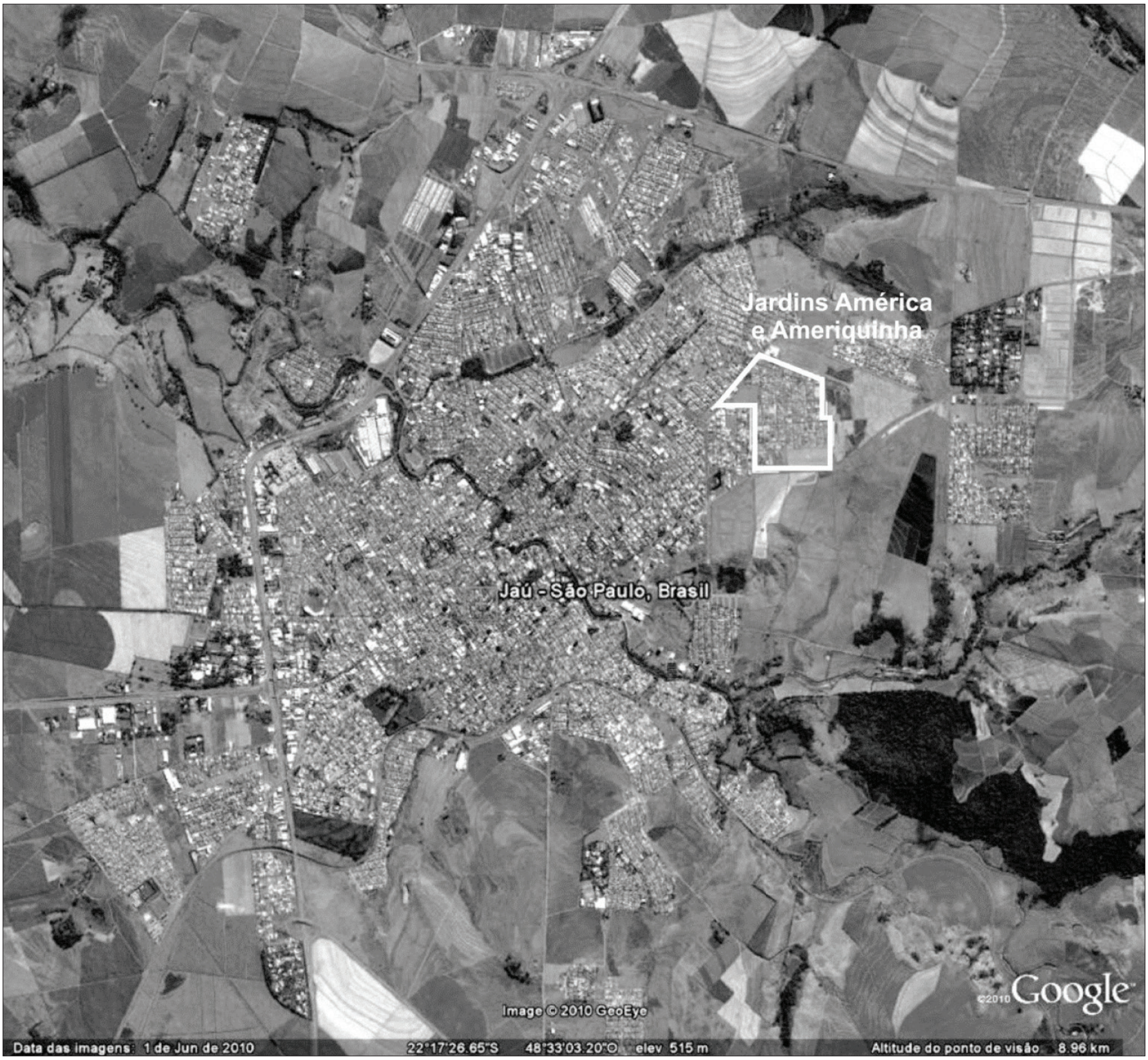

Figura 1 - Localização dos Jardins América e Ameriquinha na zona urbana do município de Jaú, São Paulo. 
O "Jogue Limpo" foi uma parceria entre a Faculdade de Tecnologia de Jahu (FATEC Jahu) e a Prefeitura Municipal de Jahu, com a colaboração da Associação de Moradores do Bairro. A primeira etapa do programa consistiu na caracterização dos resíduos sólidos urbanos gerados na cidade por meio da determinação do peso específico, da composição gravimétrica e da quantidade de resíduos gerados por habitante na cidade.

Iniciada em dezembro de 2001, a coleta seletiva nestes bairros funcionou contínua e regularmente por aproximadamente 2 anos. Era realizada por remoção "porta a porta": a população separava os resíduos "secos" (matérias recicláveis) e o caminhão específico da coleta seletiva percorria todas as ruas dos bairros uma vez por semana, às terças-feiras (inicialmente a coleta era realizada na quinta-feira, entretanto os moradores sugeriram a mudança do dia tendo em vista a maior geração de recicláveis durante o final de semana). Hoje, Jaú possui aproximadamente $20 \%$ dos bairros atendidos pela Coleta Seletiva Municipal e conta com um caminhão carroceria adaptado com gaiola para este serviço.

A escolha dos bairros para o programa de coleta seletiva e para amostragem de resíduos em 2001 foi decidida após discussões com o então Departamento Municipal de Meio Ambiente e Recursos Naturais (DEMARN), atual Secretaria Municipal de Meio Ambiente (SEMEIA), com a Secretaria de Educação e a Secretaria de Planejamento e Obras. A principal conclusão das discussões, diante dos dados apresentados, foi que os bairros, devido às características de suas construções, perfil de sua população e infraestrutura e serviços, poderiam representar a realidade da geração de resíduos urbanos da cidade.

Esses bairros apresentam residências dos mais variados padrões socioeconômicos, além de possuírem, de forma diversificada, estabelecimentos dos setores do comércio, serviços, educação, saúde e da indústria. Os bairros têm população atual de 3.388 habitantes (IBGE, 2010), aproximadamente 3\% da população do município. São 1.676 domicílios particulares ocupados, sendo 146 com finalidades não residenciais, 4 estabelecimentos de educação e 1 de saúde, além de 45 construções.

\section{Metodologia}

Foram estabelecidas duas etapas para a caracterização qualitativa e quantitativa dos resíduos gerados. A primeira consistiu em coletar os RSU dos bairros Jardim América e Ameriquinha em 30 de agosto de 2010 e $1^{\circ}$ e 3 de setembro do mesmo ano, respectivamente segunda, quarta e sexta-feira, dias da coleta regular nos bairros; e a segunda, em separar e pesar os resíduos coletados. Os resíduos sólidos domiciliares foram recolhidos em rota específica realizada pela Prefeitura Municipal de Jahu. A coleta foi realizada por um caminhão carroceria sem compactação, visando à determinação do peso específico dos resíduos. A cada viagem o veículo foi pesado (vazio e cheio) para a verificação da quantidade total de resíduos gerados em cada dia. Para a determinação da geração per capita da diária de resíduos nos bairros, a somatória do peso líquido de todas as viagens dos caminhões foi dividida por sete (número de dias da semana) e depois pelo número de habitantes do bairro, conforme a Equação 1:

$\mathrm{Q}_{\mathrm{rgh}}=\left(\left(\mathrm{C}_{1}+\mathrm{C}_{2}+\mathrm{C}_{3}+\ldots+\mathrm{C}_{\mathrm{n}}\right) * 1.000 / 7\right) / \mathrm{P}_{\mathrm{b}}$

Onde,

$\mathrm{Q}_{\mathrm{rgh}}=$ Resíduos gerados por habitante/dia estimados (g. hab ${ }^{-1}$. dia $\mathrm{d}^{-1}$ )

$\mathrm{C}_{\mathrm{n}}=$ Peso líquido dos resíduos na viagem $\mathrm{n}$ do caminhão $(\mathrm{kg})$

$\mathrm{P}_{\mathrm{b}}=$ População dos bairros Jardins América e Ameriquinha (hab)

Na sequência, o caminhão se dirigia ao aterro municipal, onde os resíduos eram descarregados em uma lona plástica para posterior separação. No dia 30 de agosto, foram feitas duas viagens de caminhão. Já nos dias $1^{\circ}$ e 3 de setembro, o recolhimento foi em apenas uma viagem diária. De cada uma delas, retiraram-se cinco amostras em tambores de 100 L. Todos os dias as amostras foram recolhidas da seguinte forma: duas na parte anterior, duas na posterior e uma no meio do caminhão.

Foram retirados para amostragem 500 L de resíduos por viagem de caminhão durante os 3 dias, conforme os procedimentos para coleta de amostras para análise de composição física sugerido pelo Instituto de Pesquisas Tecnológicas (IPT) (1995) e considerando a Associação Brasileira de Normas Técnicas - Norma Brasileira (ABNT-NBR) 10007 — Amostragem de resíduos sólidos (ABNT, 2004). Os recipientes, normalmente sacos plásticos, foram rompidos próximos aos pontos de amostragem para homogeneizar a amostra. Os tambores foram pesados (a balança foi tarada com o tambor vazio) determinando-se a massa total das amostras e o peso específico de cada um dos cinco tambores, permitindo, desta maneira, o peso específico médio das amostras. O Peso Específico $\left(\mathrm{P}_{\mathrm{e}}\right)$ foi calculado conforme segue:

$\mathrm{P}_{\mathrm{e}}=\mathrm{m} / \mathrm{v}$

Onde, $\mathrm{P}_{\mathrm{e}}=$ Peso específico da amostra $\left(\mathrm{kg} \cdot \mathrm{m}^{-3}\right)$

$\mathrm{m}=$ Massa da amostra $(\mathrm{kg})$

$\mathrm{v}=$ Volume da amostra $=0,2$ ou $0,1 \mathrm{~m}^{3}$

Após o cálculo do peso específico, o material dos tambores foi separado por componentes para determinação da composição física dos resíduos. Cada componente (matéria orgânica, rejeitos, papel e papelão, metais ferrosos, metais não ferrosos, plástico duro, plástico filme, vidros, etc.) foi pesado separadamente calculando-se o percentual em relação ao total e estimando-se a quantidade de materiais recicláveis presentes.

Os resultados obtidos foram comparados com os do Programa "Jogue Limpo" (REZENDE, 2001) e extrapolados para todo o município, permitindo a comparação dos valores obtidos com a quantidade de resíduos sólidos urbanos gerados diariamente na cidade, atualmente 
são enviados para aterro sanitário da iniciativa privada localizado em Guatapará, São Paulo - na época da amostragem, os RSU tinham como destino um aterro sanitário localizado no município de Onda Verde, no mesmo Estado.

\section{Resultados e discussões}

A Tabela 1 apresenta a quantidade de resíduos gerados por habitante diariamente nos bairros, considerando a população $\left(\mathrm{P}_{\mathrm{b}}\right)$ e a quantidade de resíduos sólidos em cada viagem do caminhão (Vn).

Levando em conta os resultados obtidos na amostragem realizada em 2001, no Programa "Jogue Limpo", nos mesmos bairros e com metodologia semelhante, foi possível constatar aumento de 34,9\% no total de resíduos gerados, diante do crescimento de 29,6\% da população no período. Isto representa $4,0 \%$ de aumento na geração per capita de resíduos, que passou de 618 para $643 \mathrm{~g}$. hab ${ }^{-1}$. dia-1 em 9 anos, conforme mostra a Tabela 2.
O valor de resíduos gerados diariamente por habitante nos bairros do estudo de caso (643 g. hab ${ }^{-1}$. dia-1), multiplicado pela população total atual do município (131.050 habitantes) leva a uma estimativa de $84.265,15 \mathrm{~kg}$ ou 84,27 toneladas de resíduos sólidos urbanos criados diariamente no município. O valor é praticamente o mesmo da quantidade total média de resíduos sólidos urbanos enviados ao aterro sanitário diariamente pela Prefeitura Municipal de Jahu nos meses de abril a agosto de 2010. A diferença das quantias foi $0,8 \%$, conforme apresentado na Tabela 3 .

Já o peso específico dos resíduos sólidos urbanos gerados foi 136,2 kg.m $\mathrm{m}^{-3}$ inferior ao calculado em 2001 (143,9 kg.m $\left.{ }^{-3}\right)$, indicando aumento do volume em relação à massa dos resíduos gerados. Esta informação é importante para o gerenciamento da coleta, transporte e disposição final no que diz respeito à determinação da capacidade volumétrica necessária para estas etapas. A Tabela 4 apresenta os resultados do peso específico dos resíduos.

Tabela 1 - Quantidade de resíduos sólidos urbanos gerados diariamente por habitante nos Jardins América e Ameriquinha, em Jaú, São Paulo, amostrados em 2010.

\begin{tabular}{|c|c|c|}
\hline Viagens & Data & Peso líquido dos caminhões \\
\hline $\mathrm{C}_{1}$ & 30 de agosto de 2010 (segunda-feira) & $4.600 \mathrm{~kg}$ \\
\hline $\mathrm{C}_{2}$ & 30 de agosto de 2010 (segunda-feira) & $2.000 \mathrm{~kg}$ \\
\hline $\mathrm{C}_{3}$ & 1ㅇ de setembro de 2010 (quarta-feira) & $4.090 \mathrm{~kg}$ \\
\hline $\mathrm{C}_{4}$ & 3 de setembro de 2010 (sexta-feira) & $4.550 \mathrm{~kg}$ \\
\hline \multicolumn{2}{|c|}{$\mathrm{C}=\mathrm{C}_{1}+\mathrm{C}_{2}+\mathrm{C}_{3}+\mathrm{C}_{4}$} & $15.240 \mathrm{~kg}$ \\
\hline \multicolumn{2}{|c|}{$\mathrm{P}_{\mathrm{b}}$} & 3.388 habitantes \\
\hline \multicolumn{2}{|l|}{$Q_{\text {rgh }}$} & $643 \mathrm{~g} \cdot \mathrm{hab}^{-1} \cdot \mathrm{dia}^{-1}$ \\
\hline
\end{tabular}

Tabela 2 - Crescimento da população e da geração de resíduos nos Jardins América e Ameriquinha, em Jaú, São Paulo.

\begin{tabular}{lcccc} 
Ano & $\begin{array}{c}\text { População do } \\
\text { município }\end{array}$ & $\begin{array}{c}\text { População dos Jardins América e } \\
\text { Ameriquinha }\end{array}$ & $\begin{array}{c}\text { Resíduos/semana } \\
\text { Jardins América e Ameriquinha }\end{array}$ & $\begin{array}{c}\text { Resíduos/habitante/dia Jardins } \\
\text { América e Ameriquinha }\end{array}$ \\
\hline 2001 & $112.469 \mathrm{hab}^{*}$ & $2.614 \mathrm{hab}^{*}$ & $11.300 \mathrm{~kg}$ & $618 \mathrm{~g} \cdot \mathrm{hab}^{-1}$. dia- \\
2010 & $131.046 \mathrm{hab}^{* \star}$ & $3.388 \mathrm{hab}^{\star \star}$ & $15.240 \mathrm{~kg}$ & $643 \mathrm{~g} \cdot \mathrm{hab}^{-1} . \mathrm{dia}^{-1}$ \\
Crescimento & $16,9 \%$ & $29,6 \%$ & $34,9 \%$ & $4,0 \%$ \\
\hline
\end{tabular}

*Instituto Brasileiro de Geografia e Estatística (IBGE, 2000); **IBGE (2010).

Tabela 3 - Resíduos sólidos urbanos de Jaú enviados ao aterro entre abril e agosto de 2010; média diária levada ao aterro e estimada, considerando os resultados da amostragem da geração de resíduos nos Jardins América e Ameriquinha, em Jaú, São Paulo.

\begin{tabular}{|lccccc} 
Mês/ano & Dias (quantidade) & Total mensal & Média diária & $\begin{array}{c}\text { Média diária enviada } \\
\text { ao aterro (ton) }\end{array}$ & $\begin{array}{c}\text { Média diária estimada } \\
\text { no estudo (ton) }\end{array}$ \\
\hline abril/2010 & 30 & $2.819,5$ ton & 93,98 ton & 81,50 ton & \\
\hline maio/2010 & 31 & $2.526,5$ ton & 84,95 ton & 84,96 \\
\hline junho/2010 & 30 & $2.548,4$ ton & 86,48 ton & 84,27 \\
\hline julho/2010 & 31 & $2.680,8$ ton & 77,88 ton & \\
\hline agosto/2010 & 31 & $2.414,3$ ton & 84,96 ton & \\
\hline Total & 153 & $12.989,5$ ton &
\end{tabular}

Tabela 4 - Peso específico dos resíduos sólidos urbanos dos Jardins América e Ameriquinha, em Jaú, São Paulo.

\begin{tabular}{lccc}
\hline Data & Peso da amostra $(\mathrm{kg})$ & Volume da amostra $\left(\mathrm{m}^{3}\right)$ & Peso específico $\left(\mathrm{kg} . \mathrm{m}^{-3}\right)$ \\
\hline 30 de agosto de 2010 & 153,0 & 1,0 & 153,0 \\
\hline 10 de setembro de 2010 & 67,8 & 0,5 & 135,6 \\
\hline 3 de setembro de 2010 & 51,7 & 0,5 & 103,3 \\
Total & 272,5 & 2,0 & 136,2 (média)
\end{tabular}


A composição gravimétrica dos RSU dos Jardins América e Ameriquinha, obtida pela análise das amostras mediante triagem e separação dos materiais em classes, indica que praticamente 50\% da massa de resíduos gerada é de matéria orgânica e $25 \%$ de rejeitos. Os materiais recicláveis representam pouco mais de $25 \%$, sendo que os plásticos ultrapassam 10\% do total dos resíduos. Os plásticos moles (embalagens e sacolas plásticas, entre outros) representam 5,9\%, e, de acordo com o estudo, são aterrados diariamente $4.972 \mathrm{~kg}$, ou seja, praticamente 5 toneladas por dia. A Figura 2 apresenta os resultados da análise da composição gravimétrica da amostragem realizada.

O percentual de matéria orgânica é praticamente o mesmo nas duas amostras, 49,1\% em 2001 e 49,4\% em 2010, enquanto a quantidade de rejeitos aumentou de 23,3 para $25,1 \%$, o percentual de plástico mole presente nos RSU foi 59\% maior em 2010, e os percentuais de embalagem longa vida, PET, plástico duro, papel, papelão, metais ferrosos e vidro foram menores.

Em 2010, os RSU apresentaram 1,7\% de couro nos resíduos amostrados enquanto em m 2001 o material não foi encontrado. Cabe salientar que em 2001, os resíduos das indústrias do setor calçadista eram coletados pela própria Prefeitura Municipal, de forma específica, sendo depositados no aterro municipal, por isso o couro não estava presente na coleta domiciliar. A partir de 2005, a responsabilidade pela coleta e destinação passou a ser dos geradores, que começaram a enviar os resíduos para um aterro industrial específico, licenciado para receber os resíduos do setor, em especial ao de couro curtidos ao cromo. A amostragem realizada, porém, demonstra que provavelmente parte dos resíduos de couro são descartados inadequadamente na coleta de lixo regular do município. A Figura 3 compara a composição gravimétrica dos RSU dos Jardins América e Ameriquinha nos anos de 2001 e 2010.

\section{Conclusões}

A composição gravimétrica dos resíduos coletados nos bairros Jardim América e Ameriquinha em 2001 e 2010 foi semelhante. Em ambas as amostragens, o percentual de matéria orgânica foi próximo de 50\%, o que apresenta a importância de estudar alternativas para a implementação de um sistema de compostagem de resíduos para o município, considerando ainda que, além deste material, há os resíduos das podas e dos serviços de jardinagem executados pelos órgãos municipais.

Entre os materiais recicláveis, os resíduos do tipo "plástico mole" apresentaram o maior crescimento percentual. Os valores calculados pelo trabalho permitem estimar aterramento diário de cinco toneladas destes materiais nos resíduos produzidos pelo município, mostrando a problemática do uso das sacolas plásticas na cidade.

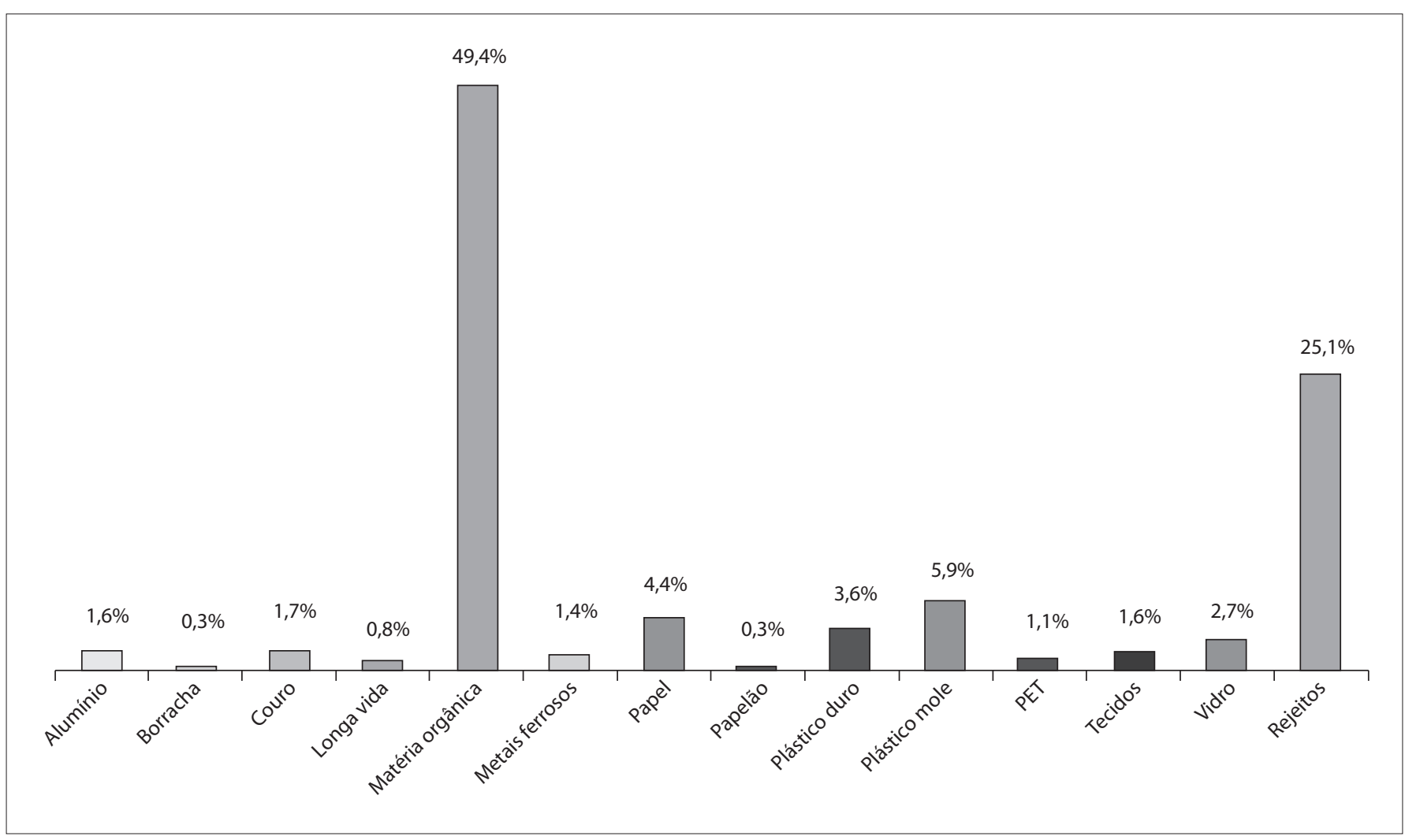

Figura 2 - Composição gravimétrica dos resíduos sólidos urbanos dos Jardins América e Ameriquinha, Jaú, São Paulo, em agosto e setembro de 2010. 


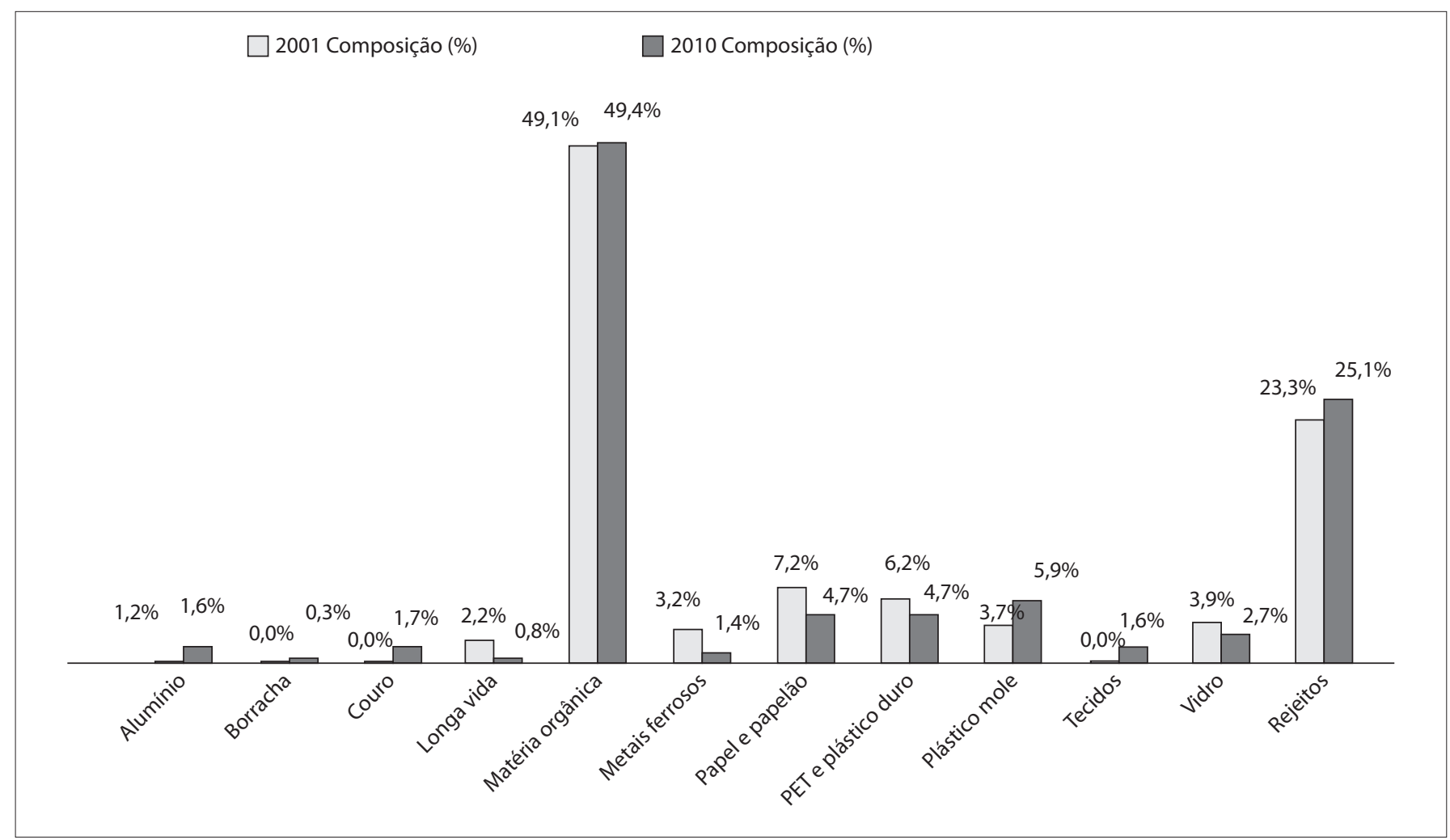

Figura 3 - Composição gravimétrica dos resíduos sólidos urbanos dos Jardins América e Ameriquinha, Jaú, São Paulo, em 2001 e 2010.

O percentual de recicláveis dos tipos embalagens longa vida e PET diminuíram em 2010 quando comparados a 2001. Os resultados provavelmente decorrem do maior valor deles no mercado de materiais recicláveis atualmente. A presença de alumínio nos resíduos a serem aterrados demonstra a ineficiência do processo de coleta seletiva e a não separação deste material por parte da população, enquanto a existência de resíduos de couro na coleta regular indica o descarte irregular de resíduos industriais. Vale destacar que Jaú é um importante polo de produção de calçados femininos e conta com centenas de indústrias do setor, que possuem um sistema próprio de coleta e destinação de seus resíduos.
A realização de amostragens periódicas, com intervalos pré-determinados, para a caracterização dos resíduos, permite o acompanhamento do desempenho dos programas de educação ambiental e coleta seletiva implementados. No estudo de caso apresentado, fica evidente a semelhança da composição gravimétrica dos resíduos sólidos urbanos nas amostragens realizadas em 2001 e 2010. Considerando que a primeira aconteceu antes da implementação do programa "Jogue Limpo" de coleta seletiva, fica evidente que os resultados do programa foram temporários. A interrupção de suas atividades levou a situação ao nível observado há uma década, mostrando a importância da continuidade das estratégias, não só da coleta seletiva, mas também de educação ambiental e de marketing.

\section{Referências}

ASSOCIAÇÃO BRASILEIRA DE EMPRESA DE LIMPEZA PÚBLICA E RESÍDUOS ESPECIAIS (ABRELPE). (2009) Panorama Nacional de Resíduos Sólidos 2009. Disponível em: < http// http://www.abrelpe.org. br/panorama_envio.cfm?ano=2009 > . Acesso em: out. de 2010.

ASSOCIAÇÃO BRASILEIRA DE NORMAS TÉCNICAS (ABNT). (2004) NBR 10007: Amostragem de resíduos. Rio de Janeiro: ABNT.

BRASIL. Secretaria Especial de Desenvolvimento Urbano da Presidência da República (SEDU). (2001) Manual de gerenciamento integrado de resíduos sólidos. Rio de Janeiro: IBAM.
FUZARO, J.A. \& RIBEIRO, L.T. (2007) Coleta seletiva para prefeituras. 5 ed. São Paulo: SMA/CPLEA.

INSTITUTO BRASILEIRO DE GEOGRAFIA E ESTATÍSTICA (IBGE). (2000) Censo 2000. Disponível em: <http://www.ibge.gov.br/home/estatistica/ populacao/default_censo_2000.shtm > . Acesso em: nov. de 2010.

INSTITUTO BRASILEIRO DE GEOGRAFIA E ESTATÍSTICA (IBGE). (2002) Pesquisa Nacional de Saneamento Básico 2000. Disponível em: <http://unw. ibge.gov.br/home/estatistica/populacao/censo2010/calendario.shtm>. Acesso em: dez. de 2010 
INSTITUTO BRASILEIRO DE GEOGRAFIA E ESTATÍSTICA (IBGE). (2010) Censo 2010. Disponível em: <http://www.ibge.gov.br/home/estatistica/ populacao/censo2010/calendario.shtm >. Acesso em: nov. de 2010.

JARDIM, N.S. \& WELLS, C. (1995) Lixo municipal: manual de gerenciamento integrado. São Paulo: IPT/CEMPRE.

MONTEIRO, J.H.P. ; FIGUEIREDO, C.E.M.; MAGALHÃES, A.F.; MELO, M.A.F.; BRITO, J.C.X.; ALMEIDA, T.P.F.; MANSUR, G.L. (2001). Manual de gerenciamento integrado de resíduos sólidos. Rio de Janeiro: IBAM.
POLAZ, C.N.M. \& TEIXEIRA, B.A.N. (2009) Indicadores de sustentabilidade para a gestão municipal de resíduos sólidos urbanos: um estudo para São Carlos (SP). Engenharia Sanitária e Ambiental, v. 14, n. 3, p. 411-420.

REZENDE, J.H. (2001) Programa Jogue Limpo Jaú. Jaú: FATEC Jahu.

SÃO PAULO. Secretaria do Meio Ambiente. (2010) Cadernos de Educação Ambiental: Resíduos Sólidos. São Paulo: SMA. 